were prevalent, their evil influence being increased by summer heat. In fact, the author comes to the conclusion that the principal causes of infantile mortality are to be found in the dwelling.

In summarising his conclusion the author states " children in summer succumb to gastro-intestinal troubles, but the former hypotheses of how this season acts cannot be confirmed. Children do not die solely, or even chiefly, as is often asserted, of decomposed milk. Milk sterilization has not given good results with us. Children do not die, as Meinert thinks, of heat stroke. . The cause of summer diarrhoea is not to be found in a single factor. If a child is to die there must be a combination of circumstances. The first is the taking of milk of the lower animals (artfremder). This causes in many children (not in all) intestinal disturbances (dyspepsia-nutrient trouble), and these constitute the foundation, the soil, on which new injurious factors can work. The latter are mostly bacterial, and the micro-oganisms effect an entrance into the child's body in various ways, most frequently by so-called 'contact,' but may also, though not so frequently as is supposed, by milk; otherwise sterilized milk would have given better results. Children in wretched dwellings and badly cared for are by far the most endangered. The influence of artificial feeding consists chiefly in causing predisposition."

The following quotation gives the principles on which the author would found his remedial measures:- "These views, especially of the small use of sterilized milk, have not a solely theoretical interest in my opinion. One must from this standpoint regret that in Germany the problem of the combating of infantile mortality in many places resolves itself into simply giving out sterilized cows' milk. Considerable sums are uselessly spent in this way. Children must be naturally nourished, but when this cannot be done they must be removed completely from those environs which are dangerous to them. They must be protected from dirt and infection." (Italics are the author's.)

The author devotes considerable space to the cost, etc., of having special "homes" or crèches which could be temporarily provided for poor people to bring their children to when they require artificial nourishment.

\section{AN EXPERIMENT IN SCARLET FEVER.}

By C. F. STOVIN, M.A., D.P.H., Medical Officer of Health, llford.

THIRTEEN cases of scarlet fever occurred at Dr. Barnardo's Village Homes, and a very interesting experiment was carried out by Dr. Milne, the Medical Officer to the Homes. The children were allowed to remain in their ordinary cottage in most instances, sleeping in the common bedroom, and after about fourteen days they were allowed to get up and mix with the other inmates of the cottage downstairs. On several occasions Dr, Milne was good enough to take me round and show me the treatment carried out. For the first twenty-four hours the throat is swabbed with carbolic oil every two to four hours. The whole body is rubbed with pure eucalyptus oil from head to foot twice in the twenty-four hours for the first four days, and once a day for the ensuing ten days, after which time the patient is presumed to be free from infection.

So far as one can judge, the treatment appeared to act satisfactorily-that is to say, there did not appear to be any spread of infection from any of the cases to those subsequently notified. On the other hand, one case that was notified was not detected until peeling was well advanced, probably about the fourteenth day, and no further case appeared in that cottage, in spite of the absence of treatment. I quote this case merely to show how careful one must be in drawing conclusions about the infectivity, or not, of a case of scarlet fever. When everything seems to point to the likelihood of the disease spreading it does not do so, and another time it seems to infect others in the most wholesale way.- Dr. Milne is strongly of the opinion that his method of treatment prevents the development of complications, nose and ear troubles.

Accordingly I carried out this line of inunction, ete., on some dozens of cases admitted to the isolation hospital, but without success in preventing complications. This result may have been due to the delay in commencing the treatment incidental to the diagnosis, notification, and removal to hospital of the cases, though, as a rule, the delay was not great. If, on extended trial, Dr. Milne's contentions are proved to be correct, it would open a new era in the treatment of scarlet fever.

\section{THE LOCAL INCIDENCE OF TIBERCULOSIS.}

WVE much regret that owing to an unfortunate error the figures for sheffield were incorrectly stated in Table $\mathrm{I}$ in the article on the Local Incidence of Tuberculosis that appeared in the July number of PuBlic Health. The correct figures are as follows:-

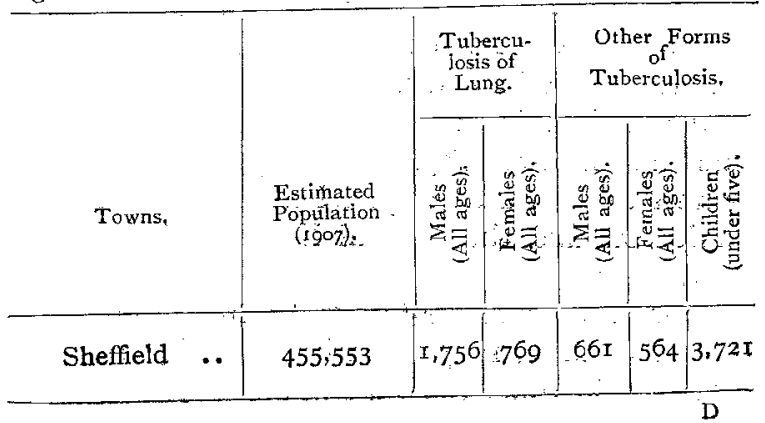

